\title{
Reality checks on microbial food web interactions in dilution experiments: responses to the comments of Dolan and McKeon
}

\author{
M. R. Landry ${ }^{1}$ and A. Calbet ${ }^{2}$ \\ ${ }^{1}$ Integrative Oceanography Division, Scripps Institution of Oceanography, University of California at San Diego, 9500 \\ Gilman Dr., La Jolla, CA 92093-0227, USA \\ ${ }^{2}$ Institut de Ciències del Mar, CMIMA (CSIC), P. Marítim de la Barceloneta 37-49, 08003 Barcelona, Spain
}

Received: 13 December 2004 - Published in Ocean Science Discussions: 29 December 2004

Revised: 17 June 2005 - Accepted: 8 July 2005 - Published: 2 August 2005

\begin{abstract}
Dolan and McKeon (2005) have recently criticized microzooplankton grazing rate estimates by the dilution approach as being systematically biased and significantly overestimated. Their argument is based on observed mortality responses of ciliated protozoa to reduced food in several coastal experiments and a global extrapolation which assumes that all grazing in all ocean systems scales to the abundance of ciliates. We suggest that these conclusions are unrealistic on several counts: they do not account for community differences between open ocean and coastal systems; they ignore direct experimental evidence supporting dilution rate estimates in the open oceans, and they discount dilution effects on mortality rate as well as growth in multi-layered, open-ocean food webs. High microzooplankton grazing rates in open-ocean systems are consistent with current views on export fluxes and trophic transfers. More importantly, significantly lower rates would fail to account for the efficient nutrient recycling requirements of these resource-limited and rapid-turnover communities.
\end{abstract}

\section{Introduction}

It has long been speculated that the gradient of food availability in dilution experiments could lead to treatment differences in the population growth rates of microzooplankton grazers (Landry and Hassett, 1982; Gallegos et al., 1989; Landry, 1993; Landry et al., 1995). This, in fact, should be the case whenever ambient concentrations of food resources are insufficient to sustain maximal rates of food intake and growth. Dolan et al. (2000) and Dolan and McKeon (2005) have demonstrated additional caveats for such experiments that ciliated protozoa may not only grow slower, but may, in fact, decline precipitously in seawater diluted to low percent-

Correspondence to: M. R. Landry

(mlandry@ucsd.edu) ages $(10 \%)$ of natural food concentration. This observation is important to those who use the technique to assess the microzooplankton grazing impacts on phytoplankton stocks and production rates. But does it mean that dilution experiments will invariably yield inflated estimates of microzooplankton grazing? In the interest of promoting a useful discussion of this point, we therefore respond to the main conceptual issues raised by Dolan and McKeon (2005) as well as several inaccuracies and misconceptions in that critique.

\section{General premise}

In order to frame the microzooplankton grazing issue for discussion, we will first consider what the Calbet and Landry (2004) synthesis of dilution results actually reported on the matter and how that relates to our understanding of microbial trophic interactions and organic matter cycling and fluxes in the oceans. Calbet and Landry (2004), for instance, did not point to the relative invariance or "near-constancy" of grazing losses, as one might be led to believe by Dolan and McKeon (2005). In fact, the analyzed data were marked by extraordinary variability, from zero grazing to $2-3$ times contemporaneous estimates of phytoplankton growth, as evident in the accompanying figures and the web-accessible data table. This variability is presumably as it should be for individual experiments that capture communities in varying states of phytoplankton increase, decline or near-steady state. We did however find that, within relatively broad categories of marine habitats and regions, the "mean" fractions of daily phytoplankton production removed by microzooplankton grazers varied modestly, from about 60 to $75 \%$ of primary production (PP). As potentially applied to the global ocean, the data average of $64 \%$ of PP could even be an underestimate because open-ocean experiments, which provided the highest mean rate estimates, were under-represented in the data

(C) 2005 Author(s). This work is licensed under a Creative Commons License. 
set relative to their contributions to ocean productivity on an areal basis.

Is $64 \%$, or presumably some slightly higher fraction, of global ocean primary production too much grazing for microherbivores? The general premise of Dolan and McKeon (2005) is that "there would be little left" for carbon export or higher level food webs. This argument does not consider however the reusable fluxes associated with trophic transfers. For instance, if $70 \%$ of PP were directly consumed by micrograzers, only about half of that would be actually lost to respiration by these primary consumers (Fenchel and Finlay, 1983; Verity, 1985), and the remainder would be available as heterotrophic biomass and as small particulate debris for further utilization and transfer. If each level of intermediate consumer in a protistan predatory chain of 2-3 links $(n)$ had a gross growth efficiency (GGE) of 0.3 (Straile et al., 1997), 32 to $36 \%$ of PP would ultimately be available to mesozooplankton (net available for transfer $=30 \%$ ungrazed $\mathrm{PP}+70 \% \times 0.3^{n}$; where $n=2$ or 3 ). Such an amount would be quite adequate to support the relatively low rates of POC export in the central open oceans (e.g. 5-10\% of PP; Karl, 1999; Landry et al., 1997). Moreover, this simple calculation does not consider any fluxes associated with protist utilization of bacterial production ( $\sim 15 \%$ of PP; Anderson and Ducklow, 2001) or small particulate egesta. High microzooplankton grazing impacts are therefore not inherently at odds with what we know about ocean export fluxes. In fact, after more than a decade of intensive JGOFS (Joint Global Ocean Flux Studies) process and time-series studies, we can reasonably say that our understanding of open-ocean systems is beginning to be quite good, and high microzooplankton grazing impacts are an integral part of that understanding.

From 16 years of approximately monthly data from the Hawaii Ocean Time-series Program, for example, we know that ${ }^{14} \mathrm{C}$-particulate production averages 15 moles $\mathrm{C} \mathrm{m}^{-2} \mathrm{y}^{-1}$ and is about half of gross production (Karl et al., 2002). Of this production, total export is 1.2 moles $\mathrm{C} \mathrm{m}^{-2} \mathrm{y}^{-1}(8 \%$ of ${ }^{14} \mathrm{C}$ production) based on the sum of particulate and dissolved fluxes of organic carbon and active transport by migrating zooplankton (Lomas et al., 2003) and consistent with independent estimates from biogeochemical mass balances and trace-gas proxies of new production (Emerson et al., 1996). Such rigorously constrained production and export estimates anchor our understanding of open-ocean oligotrophic systems as being not only consistent with high grazing, but demanding efficient return of recycled nutrients to sustain $>90 \%$ of daily primary production. While the utility of rate estimates from isolated dilution experiments might be arguable, a large fraction of the open-ocean data have come as part of integrated experimental studies in JGOFS Process and related projects, and their interpretations are both constrained by and generally consistent with contemporaneous estimates of production, export, mesozooplankton grazing and nutrient cycling (e.g. Landry et al., 1997, 2001). In the equatorial Pacific, for instance, balanced growth and grazing estimates of $\sim 1$ cell division $d^{-1}$ for Prochlorococcus and other pico-phytoplankton (Landry et al., 2003; Le Borgne and Landry, 2003) are entirely consistent with diel patterns of cell cycle properties and in situ abundances (Vaulot and Marie, 1999) and beam transmissometry estimates of particle density (Neveux et al., 2003). In other words, there is a good correspondence between rate estimates from dilution incubations in bottles and entirely independent assessments of growth and mortality processes from non-manipulative observational techniques.

Indeed, as a "reality check", one might contemplate the difficulties that arise in explaining open-ocean equilibrium conditions in the absence of high microherbivore grazing. For this thought problem, one should note that microzooplankton grazing rates from dilution experiments are measured relative to the net realized rates of phytoplankton cell growth, not the gross rates of primary carbon production, the latter being partially offset by losses to phytoplankton respiration, DOC production and bacterial uptake, viral lysis, etc. Thus, observed cell growth rates of one doubling day ${ }^{-1}$ or more for phytoplankton of the central tropical/subtropical oceans require loss terms of comparable magnitude to maintain quasi-steady state. The candidate loss processes are: 1) micrograzers, 2) larger mesozooplankton grazers, and 3) direct cell sinking to export.

There is little evidence to support massive and temporally persistent export of chlorophyll-rich material in the central open-oceans, and both the tiny size of the dominant phytoplankton (Prochlorococcus, Synechococcus) and the nutrient recycling needs for sustainable productivity provide strong arguments against such a possibility. Most mesozooplankton also cannot directly exploit tiny phytoplankton. Experimental assessments of mesozooplankton grazing impact in such regions typically range on the order of 5-10\% of daily PP (Bautista and Harris, 1992; Dagg, 1993; Dam et al., 1993, 1995; Rollwagen-Bollens and Landry, 2000), and one must typically invoke a strong predatory link through heterotrophic protists to account even for the basic metabolic requirements of these consumers (Stoecker and Capuzzo, 1990; Roman and Gauzens, 1997). These considerations leave microzooplankton grazing therefore as the most likely loss process for the vast majority of phytoplankton biomass growth, which is consistent with measurements by the dilution technique. To make this argument another way, if microzooplankton grazing impact in the open oceans is as low as suggested by Dolan and McKeon (2005), 50\% of PP, and if losses to export flux and to mesograzers are both of order $5-10 \%$ of PP, about 30 to $40 \%$ of daily PP would have no obvious mechanism for its direct utilization within the food web and for the efficient return of remineralized nutrients to phytoplankton.

In extending the above thoughts about trophic interactions and fluxes for the open oceans to more coastal environments, or even among different open-ocean regions, one must consider that similar rates of microzooplankton herbivory can 
have very different implications, depending on the position of microzooplankton in a food web context. For instance, if $60 \%$ of PP is consumed by micrograzers, and these, in turn, are "directly" consumed by mesozooplankton, then the POC pool for direct particle export or mesozooplankton consumption can be as high as $70 \%$ of PP, or about double that of the open-ocean example above, since only $30 \%$ of PP $(50 \%$ of grazed production) would be lost to microherbivore respiration. A more efficient transfer of bacterial secondary production to mesozooplankton might also occur in such a system, pushing this POC pool even higher. Different ocean regions may therefore have substantially different characteristics with respect to mesozooplankton secondary production and export flux, even while appearing to have reasonably similar rates of microherbivory. The important difference is the mean length of the protistan predatory chain to higherlevel consumers. In Landry and Calbet (2004), we provide a more detailed discussion of the implications of differing food-web scenarios for microzooplankton secondary production and trophic transfers.

\section{Methodological issues and insights}

The heart of the Dolan and McKeon (2005) commentary is its critique of the dilution methodology. We welcome such discussion as an important part of the evolution of scientific methodology, and hope that it ultimately leads to new or improved approaches. What we offer in this section is therefore not a "defense" of the method or how it is applied in different circumstances by various users. We do, however, wish to clarify certain points that we believe to be inaccurately or incompletely represented by Dolan and McKeon (2005), and to provide a few relevant insights of our own.

For one, we contest the Dolan and McKeon (2005) characterization of insignificant dilution regression statistics as experimental "failures". According to the method, the regression slope provides an estimate of the instantaneous grazing rate. Consequently, when an experiment yields an insignificant regression slope, it means that there is undetectable or "zero" grazing. A high incidence of such results, as Dolan and McKeon (2005) claim, is therefore directly contradictory to their argument that dilution experiments "are unlikely to furnish evidence of low grazing rates". In this regard, Calbet and Landry (2004) discarded very few experimental results from the literature as problematic and averaged zero values with all of the other estimates. Moreover, all of the ratio data were arctan transformed so as not to exaggerate the relative importance of grazing values far in excess of $100 \%$ PP. In contrast, the analysis by Dolan and McKeon (2005) was highly selective, excluding all experimental results where grazing rate was measurably low, as indicated by an insignificant regression slope.

A second arguable issue in the Dolan and McKeon (2005) critique is that they cite both Dolan et al. (2000) and Gallegos
(1989) as providing supporting evidence for over-estimated grazing rates. While the former is accurate, the latter is misleading. The main point of the Gallegos (1989) paper was the observation of saturated protistan grazing kinetics under high food conditions, which led to "underestimates" of grazing impact in dilution experiments conducted. What is more interesting about the Gallegos (1989) and Dolan et al. (2000) papers is that they both involved experiments in the Rhode River Estuary (Maryland, USA), one leading to underestimates of grazing, the other to overestimates. If one cannot make an unambiguous case for systematic biases among a handful of experiments conducted in a given system, how can systematic biases be reasonably extrapolated to all of the oceans?

Be that as it may, it is clear that the reduced food concentrations in a dilution series can impact protistan growth rates (Dolan et al., 2000) and that should have some effect on the regression analyses for grazing rates. In an openocean study in the equatorial Pacific, Landry et al. (1995) addressed this uncertainty using fluorescently labeled bacteria (FLB) as a grazing probe, the notion being that the regression relationship could be based on actual rates of relative grazing in different dilution treatments (FLB disappearance) rather than initial dilution estimates of the grazer community. The results of these experiments yielded essentially identical grazing rates estimates to the standard dilution regressions. Moreover, the FLB disappearance rates were entirely consistent with the estimated grazing rates on a similarly sized natural prey (Synechococcus), indicating a clear grazermediated effect. Thus, while Dolan and McKeon (2005) only speculate about dilution effects on grazer activity in the open oceans, there are available techniques and experimental results that support the published rate estimates. How then do we reconcile the expected dilution effect on population growth rate with the demonstrated negligible impact on rate estimates?

As in any natural system, the dynamics of populations in the dilution incubations are not determined by growth rates alone, but by imbalances in growth and mortality losses. In subtropical waters off Hawaii, for example, Calbet and Landry (1999) and Calbet et al. (2001) demonstrated that there are multiple levels of intermediate consumers between the size range of dominant bacterial and small eukaryotic prey and the nominal size of small ciliates. It is therefore fair to say that oligotrophic open-ocean communities of this type are complex in the sense of having a strong predator hierarchy or network of interacting populations. In addition, strategies such as mixotrophy (i.e. photosynthetic phagotrophs) are relatively widespread and may isolate at least some populations from serious starvation responses to reduced food concentrations. We hypothesize that such complexities lend themselves well to dilution manipulation in the open ocean. For instance, if we can assume that the bioenergetics of small flagellates are such that they grow in proportion to their food intake (e.g. Fenchel and Findlay, 1983), then diluting their 
food will result in a proportional decrease in growth rate. Simultaneously, however, the direct predators of small flagellates, and thus the mortality impact on the flagellates, will also be diluted by the same factor. These counteracting effects may or may not precisely offset one another in practice, but it is important to recognize that they exist and may help to explain a quasi-constancy of grazer populations, and grazing activity, when complex microbial communities are serially diluted. Problems clearly arise, however, at the level of the top consumer, which presumably would suffer all of the disadvantages of having its food reduced without a corresponding relative reduction in losses to predators. At least in principle, the presence of small starvation-resistant metazoan consumers (e.g. Oithona, Oncaea spp.) can provide topconsumer stability to protistan populations in open-ocean dilution incubations.

\section{Ciliates as community grazing proxies}

Dolan and McKeon (2005) advance the notion that the abundance of ciliated protozoa can be used as a proxy to test the "reliability" of microzooplankton community grazing estimates across varying ocean habitats. If so, then zooplankton ecologists should be able to scale total mesozooplankton grazing to the abundance of copepods. Such arguments are clearly flawed. Ciliates, as copepods, vary enormously in their sizes, discriminations and activities. Ciliates, as copepods, are just parts of grazer assemblages that vary in relative abundance and impact with physically associated shifts in the dominance structure of phytoplankton prey. Other factors, e.g. environmental temperatures, should also be relevant in comparing rate estimates from the tropics to polar systems. What Dolan and McKeon (2005) most clearly show in their data syntheses are: 1) that the abundances of important categories of grazers, nano- and dinoflagellates, are poorly correlated with and poorly predicted by ciliates, and 2) that grazing rates, particularly in low chlorophyll regions of the ocean, cannot be adequately explained by ciliates alone. The fact that their grazing analysis leaves unexplained residuals does not, in and of itself, constitute evidence that the rate estimates are systematically biased. What could be biased is their underlying assumption, which does not account for the possibility of changed community composition and function in low-chlorophyll systems. One potentially important point in this regard is that small heterotrophic flagellates may feed principally on heterotrophic bacteria in richer coastal systems, and their grazing there would be largely irrelevant to and not even measured in chlorophyll-based dilution experiments. In the low chlorophyll regions of the open oceans, however, similarly sized flagellates would feed directly on the dominant phytoplankton (photosynthetic bacteria). Thus, similar concentrations of heterotrophic flagellates in different regions of the oceans could reasonably have very different implications with regard to grazing on phytoplankton.
Are there significant structural and functional differences in the micro-herbivore assemblages of coastal and openocean ecosystems, specifically with regard to the ratio of herbivorous ciliates to flagellates (the latter including dinoflagellates)? We cannot answer this question globally, but major biomes of the Pacific Ocean and Arabian Sea, where much of the global data from open-ocean dilution experiments have been derived, clearly suggest a reduced role for ciliates in the open oceans. For example, Verity et al. (1996) indicated that ciliates comprised only $1-2 \%$ of the combined biomass of heterotrophic flagellates and ciliates during JGOFS EqPac studies in the central equatorial Pacific in 1992. More recent studies in the Northeast equatorial Pacific (Yang et al., $2004)$ indicated higher ciliate estimates (18-27\% of the flagellate and ciliate total biomass), but still much lower than one would expect for ciliates to contribute $50 \%$ to microzooplankton grazing, as assumed by Dolan and McKeon (2005). Similarly, ciliates comprised 7-32\% of flagellateciliate biomass during four spatially extensive JGOFS cruises in the Arabian Sea (Garrison et al., 2000). Because community compositional differences in the open ocean could explain most of the discrepancies noted between actual experimental results and the ciliate-based grazing estimates by Dolan and McKeon (2005), it would be worth the effort to look at community structure and function issues more carefully and critically than can be done here. Very different sampling and preservation strategies have been used in literature assessments of community composition, with implications for optimal quantification of the major groups of protistan grazers. Moreover, since mixotrophs likely play an increasing role as grazers of pico-sized phytoplankton in nutrientdeficient regions, they need to be explicitly considered in such an analysis. One would not expect an accurate accounting of flagellate grazing potential, for example, if we ignored this potentially important, but often cryptic, component of the grazing community.

Dolan and McKeon (2005) use their ciliate-proxy analysis to focus principally on potential inadequacies in grazing rate estimates from open-ocean systems. For richer, e.g. coastal, systems the apparent reasonableness of rate estimates relative to ciliates present would seem to suggest that they are "acceptable". While the latter inference would be welcome news, we wonder whether this is really the case. From our perspective, as presented above, we would predict that food-web complexities and longer trophic path lengths of open-ocean (low chlorophyll) systems should make community grazing estimates from dilution experiments more reliable there than those from systems in which ciliates represent both the dominant grazers and the top microbial consumer. These latter, richer systems are the very places where dilution-reduced food effects on growth might not be counterbalanced by reduced predation mortality. They are consequently the places where the starvation and growth rate effects described by Dolan et al. (2000) might be most important. It therefore could be the case that microzooplankton 
grazing impacts in coastal and open-ocean habitats may not be as similar as the available data presently suggests (e.g. Calbet and Landry, 2004). This remains to be determined.

\section{Concluding comments}

Dolan et al. (2000) and Dolan and McKeon (2005) have shown that coastal ciliate populations can respond adversely to dilution of their food resources and that this starvation effect can lead to overestimates of grazing rates by the dilution technique. Previous work (Gallegos, 1989) has demonstrated that grazing rates can be underestimated when ambient food conditions exceed those that saturate ingestion rates of the microzooplankton consumers. Careful work therefore needs to be done to test for either of these effects in applications of the dilution technique and to account for them in experimental rate interpretations.

In our opinion, the Dolan and McKeon (2005) critique goes wrong in extrapolating their results with one class of grazer in coastal food webs to experimental studies in openocean ecosystems, and more importantly in drawing conclusions about systematic biases in global grazing estimates. We certainly do not contend that dilution rate estimates are perfect in every, or perhaps even any, regard, or that all applications of the technique are done equally well. We do, however, suggest that there is reasonable cause to believe, in particular, the rate estimate from open-ocean (low chlorophyll) regions. Although Dolan and McKeon (2005) see grazing biases and artifacts whenever measured rates cannot be explained by the number of ciliates present, this notion does not pass several reality checks. First, good evidence exists that community compositions in low-chlorophyll regions of the open ocean can be strikingly different from coastal ecosystems, with ciliates being much less important on both a standing stock and functional basis (as grazers of Chl $a$ ) in the open ocean. We do not claim that ciliates are always under-represented in such environments, but we reject the assumption that microzooplankton grazing impacts are always and everywhere exactly two times the rate estimates inferred from ciliate abundance. Second, there is direct experimental evidence from fluorescently labeled grazing probes in low-chlorophyll, open-ocean waters that support rate estimates and interpretations of dilution experiments. Third, the dominant grazers in such systems, namely small flagellates, are deeply embedded in the size hierarchy of protistan consumers where dilution is accompanied by compensatory growth and mortality effects. Both growth and mortality effects need to be considered when projecting the "net effects" of dilution. Lastly, the general premise of the Dolan and McKeon (2004) critique does not accurately reflect current views of open-ocean plankton dynamics. High microzooplankton grazing rates in low-chlorophyll openocean systems are entirely consistent with the export fluxes, trophic transfers and efficient nutrient recycling requirements of these resource-limited, self-sustaining and rapid-turnover communities.

The above having been said, dilution experiments should certainly not be viewed as $100 \%$ reliable or the gold standard of microzooplankton grazing assessments. They are hopefully just a crude beginning to quantifying growth and grazing rates and their relationships in the oceans. This exchange of comments with Dolan and McKeon (2005) has been useful in clarifying different perspectives on where we currently stand in terms of our understanding of microzooplankton in the oceans. It especially indicates the need for more and better information on the abundances, energetics and rate capabilities of different micro-herbivore groups, both to enhance our measurement capabilities and to understand the results more clearly in the context of ocean phenomena and dynamics.

Acknowledgements. This work was supported by National Science Foundation Grants OCE-0322074, -0336500, and -034666 (MRL) and CTM2004-02575/MAR, Program Ramón y Cajal from the Ministry of Education and Science of Spain (AC).

Edited by: J. M. Huthnance

\section{References}

Anderson, T. R. and Ducklow, H. W.: Microbial loop carbon cycling in ocean environments studied using a simple steady-state model, Aquat. Microb. Ecol. 26, 37-49, 2001.

Bautista, B. and Harris, R. P.: Copepod gut contents, ingestion rates and grazing impact on phytoplankton in relation to size structure of zooplankton and phytoplankton during a spring bloom, Mar. Ecol. Prog. Ser., 82, 41-50, 1992.

Calbet, A. and Landry, M. R.: Mesozooplankton influences on the microbial food web: Direct and indirect trophic interactions in the oligotrohic open-ocean, Limnol. Oceanogr., 44, 1370-1380, 1999.

Calbet, A. and Landry, M. R.: Phytoplankton growth, microzooplankton grazing and carbon cycling in marine systems, Limnol. Oceanogr., 49, 51-57, 2004.

Calbet, A., Landry, M. R., and Nunnery, S.: Bacteria-flagellate interactions in the microbial food web of the oligotrophic subtropical North Pacific, Aquat. Microb. Ecol., 23, 283-292, 2001.

Dagg, M.: Grazing by the copepod community does not control phytoplankton in the subarctic Pacific Ocean, Prog. Oceanogr., 32, 163-183, 1993.

Dam, H. G., Miller, C. A., and Jonasdottir, S. H.: The trophic role of mesozooplankton at $47^{\circ} \mathrm{N}, 20^{\circ} \mathrm{W}$ during the North Atlantic bloom experiment, Deep-Sea Res. II, 40, 197-212, 1993.

Dam, H. G., Zhang, X., Butler, M., and Roman, M. R.: Mesozooplankton grazing and metabolism at the equator in the central Pacific: implications for carbon and nitrogen fluxes, Deep-Sea Res. II, 42, 735-756, 1995.

Dolan, J. R., Gallegos, C. L., and Moigis, A.: Dilution effects on microzooplankton in dilution grazing experiments, Mar. Ecol. Prog. Ser., 200, 127-139, 2000.

Dolan, J. R. and McKeon, K.: The reliability of grazing rate estimates from dilution experiments: Have we over-estimated rates 
of organic carbon consumption by microzooplankton?, Ocean Sci., 1, 1-7, 2005, SRef-ID: 1812-0792/os/2005-1-1.

Emerson, S., Quay, P., Karl, D., Winn, C., Tupas, L., and Landry, M.: Experimental determination of the organic carbon flux from open-ocean surface waters, Nature, 389, 951-954, 1997.

Fenchel, T. and Finlay, B. J.: Respiration rates in heterotrophic, free-living protozoa, Microbial Ecol., 9, 99-122, 1983.

Gallegos, C. L.: Microzooplankton grazing on phytoplankton in the Rhode River, Maryland: nonlinear feeding kinetics, Mar. Ecol. Prog. Ser., 57, 23-33, 1989.

Garrison, D. L., Gowing, M. M., Huges, M. P., Campbell, L., Caron, D. A., Dennett, M. R., Shalapyonok, A., Olson, R. J., Landry, M. R., Brown, S. L., Liu, H.-B., Azam, F., Steward, G. F., Ducklow, H. W., and Smith, D. C.: Microbial food web structure in the Arabian Sea: A US JGOFS study, Deep-Sea Res. II, 47, 13871422, 2000.

Karl, D. M.: A sea of change: Biogeochemical variability in the North Pacific Subtropical Gyre. Ecosystems 2, 181-214, 1999.

Karl, D. M., Bidigare, R. R., and Letelier, R.: Sustained and aperiodic variability in organic matter production and phototrophic microbial community structure in the North Pacific Subtropical Gyre, in: Phytoplankton Productivity - Carbon Assimilation in Marine and Freshwater Ecosystems, edited by: le B. Williams, P. J., Thomas, D. R., and Reynolds, C. S., Blackwell Publ., London, 222-264, 2002.

Landry, M. R.: Estimating rates of growth and grazing of phytoplankton by dilution, edited by: Kemp, P. F., Sherr, B. F., Sherr, E. B., and Cole, J. J., Current Meth. Aquat. Microb. Ecol., 1993.

Landry, M. R., Barber, R. T., Bidigare, R. R., Chai, F., Coale, K. H., Dam, H. G., Lewis, M. R., Lindley, S. T., McCarthy, J. J., Roman, M. R., Stoecker, D. K., Verity, P. G., and White, J. R.: Iron and grazing constraints on primary production in the central equatorial Pacific: An EqPac synthesis, Limnol. Oceanogr., 42, 405-418, 1997.

Landry, M. R., Brown, S. L., Neveux, J., Dupouy, C., Blanchot, J., Christensen, S., and Bidigare, R. R.: Phytoplankton growth and microzooplankton grazing in high-nutrient, low-chlorophyll waters of the equatorial pacific: Community and taxon-specific rate assessments from pigment and flow cytometric analyses, J. Geophys. Res., 108, C12, 8142, doi:10.1029/2000JC000744, 2003.

Landry, M. R. and Calbet, A.: Microzooplankton production in the oceans, ICES J. Mar. Sci., 61, 501-507, 2004.

Landry, M. R., Constantinou, J., and Kirshtein, J.: Microzooplankton grazing in the central equatorial Pacific during February and August, 1992, Deep-Sea Res. II, 42, 657-671, 1995.
Landry, M. R. and Hassett, R. P.: Estimating the grazing impact of marine micro-zooplankton, Mar. Biol., 67, 283-288, 1982.

Landry M. R., Kirshtein, J., and Constantinou, J.: A refined dilution technique for measuring the community grazing impact of microzooplankton, with experimental tests in the central equatorial Pacific, Mar. Ecol. Prog. Ser., 120, 53-63, 1995.

Landry, M. R., Selph, K. E., Brown, S. L., Abbott, M. R., Measures, C. I., Vink, S., Allen, C. B., Calbet, A., Christensen, S., and Nolla, H.: Seasonal dynamics of phytoplankton in the Antarctic Polar Front region at $170^{\circ} \mathrm{W}$, Deep-Sea Res. II., 49, 1843-1865, 2002.

Le Borgne, R. and Landry, M. R.: EBENE: A JGOFS investigation of planktonic variability and trophic interactions in the equatorial Pacific $\left(180^{\circ}\right)$, J. Geophys. Res., 108, C12, 8136, doi:10.1029/2000JC001252, 2003.

Lomas, M. W., Bates N. R., Knap, A. H., Karl, D. M., Lukas, R., Landry, M. R., Bidigare, R. R., Steinberg, D. K., and Carlson, C.A.: Refining our understanding of oceanic biogeochemistry and ecosystem functioning, EOS, 83, 559, 566-567, 2002.

Neveux, J., Dupouy, C., Blanchot, J., Lebouteiller, A., Landry, M. R., and Brown, S. L.: Diel dynamics of chlorophylls in HNLC waters of the equatorial Pacific $\left(180^{\circ}\right)$ : Interactions of growth, grazing, physiological responses and mixing, J. Geophys. Res., 108, C12, 8140, doi:10.1029/2000JC000747, 2003.

Rollwagen Bollens, G. C. and Landry, M. R.: Biological response to iron fertilization in the eastern equatorial Pacific (IronEx II). II. Mesozooplankton abundance, biomass, depth distribution and grazing, Mar. Ecol. Prog. Ser., 201, 43-56, 2000.

Roman, M. R. and Gauzens, A.L.: Copepod grazing in the Equatorial Pacific, Limnol. Oceanogr., 42, 623-634, 1997.

Stoecker, D. K. and Capuzzo, J. M.: Predation on Protozoa: Its importance to zooplankton, J. Plank. Res., 12, 891-908, 1990.

Vaulot, D. and Marie, D.: Diel variability of photosynthetic picoplankton in the equatorial Pacific, J. Geophys. Res., 104, 3297-3310, 1999.

Verity, P. G.: Grazing, respiration, excretion and growth rates of tintinnids, Limnol. Oceanogr., 30, 1268-1282, 1985.

Verity, P., Stoecker, D. K., Sieracki, M. E., and Nelson, J. R.: Microzooplankton grazing of primary production at $140^{\circ} \mathrm{W}$ in the equatorial Pacific, Deep-Sea Res. II, 43, 1227-1255, 1996.

Yang, E. J., Choi, J. K., and Hyun, J.-H.: Distribution and structure of heterotrophic protist communities in the northeast equatorial Pacific Ocean, Mar. Biol., 146, 1-15, 2004. 